\title{
Frictional behaviour of three critical geosynthetic interfaces
}

\author{
B. M. Bacas ${ }^{1}$, J. Cañizal ${ }^{2}$ and H. Konietzky ${ }^{3}$ \\ ${ }^{1}$ Civil Engineer, Geotechnical Engineering Terrasolum S. L. Technology Development Center of University \\ of Cantabria (CDTUC) Mod 107, Avda. los Castros s/n 39005 Santander, Spain, \\ Telephone: +34942272685; Telefax: +34942272685; E-mail: bacasb@terrasolum.es \\ (corresponding author) \\ ${ }^{2}$ Professor of Geotechnical Group, School of Civil Engineering of University of Cantabria. Avda. los \\ Castros sln 39005 Santander, Spain, Telephone: +34942201813; Telefax: +34942201821; \\ E-mail: canizalj@unican.es \\ ${ }^{3}$ Professor and Chair for Rock Mechanics, Geotechnical Institute. TU Bergakademie Freiberg. \\ Gustav-Zeuner-Str. 1, D-09596 Freiberg, Germany, Telephone: +493731393453; \\ Telefax: +493731393501; E-mail: heinz.konietzky@ifgt.tu-freiberg.de
}

Received 13 January 2015, revised 30 April 2015, accepted 10 May 2015, published 11 August 2015

\begin{abstract}
This paper's scope is the shear interaction mechanisms of three critical geosynthetic interfaces (geotextile/geomembrane; drainage geocomposite/geomembrane and soil/geomembrane) typically used for lined containment facilities such as landfills. A large direct shear machine was used to carry out 159 geosynthetic interface tests. The results showed strain softening behaviour, a very small dilatancy, $0.1-1 \mathrm{~mm}$, and non-linear failure envelopes at normal stress range of $25-500 \mathrm{kPa}$. The three types of interfaces present the same main interaction mechanisms: interlocking and friction. For geotextile/geomembrane and drainage geocomposite/geomembrane interfaces, the higher the asperity height, the higher the interface shear strength. Whereas for soil/geomembrane interfaces, the higher the soil shear strength, the higher the interface shear strength. The drainage geocomposite/geomembrane interface showed the lowest friction angles, followed by the geotextile/geomembrane and the soil/ geomembrane interfaces.
\end{abstract}

Keywords: Geosynthetics, Interface shear strength, Friction angle, Critical interfaces, Direct shear test

REFERENCE: Bacas, B. M., Cañizal, J. and Konietzky, H. (2015). Frictional behaviour of three critical geosynthetic interfaces. Geosynthetics International, 22, No. 5, 355-365.

[http://dx.doi.org/10.1680/gein.15.00017]

\section{INTRODUCTION}

The main functions of a municipal solid waste landfill are: maximum accumulation of waste in the smallest possible space, isolation the waste from natural surroundings and maintaining security as well as future possible usage after its closure. Landfills are mainly isolated by geosynthetic protection layers, which interact on geosynthetic/ geosynthetic and geosynthetic/soil interfaces. It is known that to ensure stability of a landfill, knowledge of the shear behaviour of these interfaces is critical. This issue has been investigated thoroughly in recent decades (some of the most recent papers are Fox and Kim (2008), McCartney et al. (2009), Palmeira (2009), Eid (2011), Fox and Ross (2011), Brachman and Sabir (2013), Vieira et al. (2013), Liu and Martinez (2014), Sayeed et al. (2014), Fox and Stark (2015)).

The objective of this paper was to study the shear behaviour of three critical geosynthetic interfaces, geotextile/geomembrane (GT/GM), drainage geocomposite/geomembrane (GC/GM) and soil/geomembrane (soil/GM), providing an even deeper understanding than those presented in other studies. The large direct shear test has been used to carry out this testing programme since the applied normal stress range was between 25 and $500 \mathrm{kPa}$. Both Giroud et al. (1990) and Briançon et al. (2011) pointed out that for very low normal stress (lower than $25 \mathrm{kPa}$ ), the inclined plane test should be used.

The GT/GM interfaces can be used for both, lining and cover systems of the landfills. Geomembranes are typically used as a hydraulic barrier and geotextiles protect it from damage that may occur in some situations, such as high normal stresses and angular soil particles. These types of interfaces have been previously studied by Giroud et al. (1990), Koutsourais et al. (1991), Giroud and Darrasse (1993), Gilbert and Byrne (1996), Stark et al. (1996), Jones and Dixon (1998), Wasti and Özdüzgün (2001), Hebeler et al. (2005), Bergado et al. (2006), Pitanga et al. (2009) and Kim and Frost (2011). The GT/GM interface was studied by means of the results of eighteen different interfaces using three types of geotextiles and five types of geomembranes. 
The drainage GC/GM interfaces are widely used in landfill sealings, especially in cover systems. This interface minimises rainfall infiltration into a solid waste landfill. The geocomposite prevents the water from flowing into the waste. GC/GM interfaces have been investigated by Giroud et al. (1990) and Stark et al. (1996). This kind of interface was analysed with twelve different interfaces using two types of geocomposites and five types of geomembranes.

Lastly the soil/GM interfaces are an important part of the landfills' foundation and are also used to waterproof reservoirs. The soil is heavily compacted creating a geologic barrier to prevent the leachate from reaching the natural ground. Soil/GM interfaces have been studied by Seed and Boulanger (1991), Stark and Poeppel (1994), Zettler et al. (2000), Sharma et al. (2007), Eid (2011) and Fox et al. (2011). This type of interface was investigated by means of eleven different interfaces using three different soils and five types of geomembranes.

In the present study a methodology based on the ASTM D5321 was applied to carry out direct shear tests for different types of interfaces. The means to grip the different geosynthetics inside the shear box and the suitable test parameters (shear displacement rate, consolidation time and hydration time) were established based on studies from Stark and Poeppel (1994), Stark et al. (1996), Fox et al. (1997), Jones and Dixon (1998), Fox et al. (1998), Eid et al. (1999), Triplett and Fox (2001), Zornberg et al. (2005), Sharma et al. (2007) and McCartney et al. (2009). The relationships analysed were the interface shear strength versus shear displacement, the shear displacement versus normal displacement and the interface shear strength versus normal stress.

\section{EXPERIMENTAL WORK}

\subsection{Materials}

Table 1 presents the physical characteristics of different types of geosynthetics that were used for the direct shear tests.

- Three nonwoven geotextiles: GT1 $\left(500 \mathrm{~g} / \mathrm{m}^{2}\right)$ was made of needle-punched monofilaments; GT2 $\left(500 \mathrm{~g} / \mathrm{m}^{2}\right)$ was made of needle-punched staple fibres and GT3 $\left(335 \mathrm{~g} / \mathrm{m}^{2}\right)$ was made of thermally bonded monofilaments.

- Five geomembranes, $1.5 \mathrm{~mm}$ thick: GM had smooth surfaces; GMr1 and GMr4 had irregular heavy textured surfaces smaller than $1 \mathrm{~mm}$; GMr2s1 and $\mathrm{GMr} 3$ showed regular evenly spread asperities larger than $1 \mathrm{~mm}$; GMr2s2 exhibited regular spread asperities smaller than $1 \mathrm{~mm}$.

- Two drainage geocomposites: GC1 consisted of two nonwoven needle-punched geotextiles (200 and $300 \mathrm{~g} / \mathrm{m}^{2}$ ) thermally bonded to a geonet. GC2 consisteds of two nonwoven needle-punched geotextiles $\left(120\right.$ and $\left.140 \mathrm{~g} / \mathrm{m}^{2}\right)$ thermally bonded to a geonet. The type of geonet was the same for both geocomposites. The geonet had two strands with an angle of $70^{\circ}$ in the machine direction and $110^{\circ}$ in the cross machine direction.

Table 2 presents the characteristics of the three soils employed for testing, which were part of the foundation of three landfills in Spain. The soil S1 and S2 came from landfills in Cataluña and S3 came from a landfill in Albacete. The soil S3 presented a larger plasticity index than $\mathrm{S} 1$ and $\mathrm{S} 2$.

Tables 3, 4 and 5 summarise the different GT/GM, GC/GM and soil/GM interfaces tested as well the testing conditions.

\subsection{Testing equipment}

The tests on geosynthetics were carried out with a large direct shear machine. The shear box was $300 \mathrm{~mm}$ long and $300 \mathrm{~mm}$ wide and therefore fulfilled the minimum requirement. The tests were performed with a constant shear rate and fixed normal stress. The shear box was divided into a moving lower part and a static upper part. One geosynthetic was fastened to the lower box, whereas the other one was fastened to the upper box. Different gripping systems were used for the different types of geosynthetics. The geotextiles were gripped with a double-sided adhesive tape. This system worked well for the range of normal stresses tested.

Based on the studies of Fox et al. (1997, 1998) a particularly textured plate was designed to grip the geosynthetic clay liners, drainage geocomposites and geomembranes. The dimension of this plate was $300 \mathrm{~mm} \times 285 \mathrm{~mm} \times 10 \mathrm{~mm}$. The top face had pyramids of $1 \mathrm{~mm}$ height placed quincunx. The bottom face had channels that ran along the drainage holes allowing the water flow (Bacas et al. 2011). This piece was screwed on to a metal support that was placed into the direct shear box. The top side was in contact with the geosynthetic and the bottom side was in contact with the metal support. Figure 1 shows three sketches of the arrangement of the geosynthetic samples inside the direct shear machine.

\subsection{Procedures}

The direct shear tests were performed in accordance with the ASTM D5321 method.

The GT/GM interfaces were tested under wet conditions (Table 3) and the drainage GC/GM were tested under dry conditions (Table 4). It is worth mentioning the studies of Byrne et al. (1992), Mitchell and Mitchell (1992) and Bergado et al. (2006) in which they showed that the water content did not significantly affect the interface shear strength. The soil/GM interfaces were tested under dry conditions (Table 5) because both the compacted soil and geomembranes were highly impermeable and the interface would require a lot of time to be saturated.

The hydration time was $24 \mathrm{~h}$ for geotextiles, these samples were submerged into tap water inside a humid chamber (temperature $21^{\circ} \mathrm{C}$, humidity $96 \%$ ). The geomembranes were not hydrated. The consolidation time was $10 \mathrm{~min}$ inside the shear machine and the constant shear rate was $5 \mathrm{~mm} / \mathrm{min}$ for GT/GM and GC/GM and 
Table 1. Type of geosynthetics

\begin{tabular}{|c|c|c|c|c|c|c|}
\hline Geosynthetic & Label & Type $^{\mathrm{a}}$ & $\begin{array}{l}\text { Raw material }{ }^{\mathrm{b}} / \text { Type of } \\
\text { fibre }\end{array}$ & Manufacturing process & $\begin{array}{l}\text { Mass/area or } \\
\text { density }\end{array}$ & $\begin{array}{l}\text { Thickness }^{\mathrm{c}} \\
(\mathrm{mm})\end{array}$ \\
\hline \multirow[t]{4}{*}{ Geotextiles } & GT1 & NW & PP/monofilament & Needle-punched & $500 \mathrm{~g} / \mathrm{m}^{2}$ & $4 \pm 0.2$ \\
\hline & GT2 & NW & $\mathrm{PP} /$ staple fibres & Needle-punched & $500 \mathrm{~g} / \mathrm{m}^{2}$ & $5 \pm 0.6$ \\
\hline & GT3 & NW & $70 \%$ PP $30 \%$ PE & Thermally bonded & $335 \mathrm{~g} / \mathrm{m}^{2}$ & $2 \pm 0.2$ \\
\hline & & & /monofilament & & & \\
\hline \multirow[t]{5}{*}{ Geomembranes } & GMr1 & $\begin{array}{l}\text { Textured } \\
\qquad(\sim 0.5 \mathrm{~mm})^{\mathrm{d}}\end{array}$ & HDPE & $\begin{array}{l}\text { Coextrusion with } \\
\text { nitrogen gas }\end{array}$ & $\geq 0.94 \mathrm{~g} / \mathrm{cm}^{3}$ & 1.5 \\
\hline & GMr2 & $\begin{array}{l}\text { Textured }(\mathrm{s} 1: \sim 1.2 \\
\quad \mathrm{s} 2: \sim 0.8)^{\mathrm{d}}\end{array}$ & HDPE & Calendered structured & $\geq 0.94 \mathrm{~g} / \mathrm{cm}^{3}$ & 1.5 \\
\hline & GMr3 & Textured $(\sim 1.3)$ & HDPE & $\begin{array}{l}\text { Structred same resin as } \\
\text { base }\end{array}$ & $0.94 \mathrm{~g} / \mathrm{cm}^{3}$ & 1.5 \\
\hline & GMr4 & Textured $(\sim 0.25)$ & HDPE & $\begin{array}{l}\text { Coextrusion with } \\
\text { nitrogen gas }\end{array}$ & $\geq 0.93 \mathrm{~g} / \mathrm{cm}^{3}$ & 1.4 \\
\hline & GMs & Smooth & HDPE & Flat sheet extrusion & $0.94 \mathrm{~g} / \mathrm{cm}^{3}$ & 1.5 \\
\hline \multirow{2}{*}{$\begin{array}{l}\text { Drainage } \\
\quad \text { Geocomposite }\end{array}$} & $\mathrm{GC1}$ & $\begin{array}{l}\text { NW(200)/Geonet/ } \\
\text { NW(300) }\end{array}$ & $\begin{array}{l}\text { PP (geotextile), } \\
\text { HDPE (geonet) }\end{array}$ & Thermally bonded & $950 \mathrm{~g} / \mathrm{m}^{2}$ & 5 \\
\hline & $\mathrm{GC} 2$ & $\begin{array}{l}\text { NW(120)/Geonet/ } \\
\text { NW(140) }\end{array}$ & $\begin{array}{l}\text { PP (geotextile), } \\
\text { HDPE (geonet) }\end{array}$ & Thermally bonded & $710 \mathrm{~g} / \mathrm{m}^{2}$ & 5 \\
\hline
\end{tabular}

${ }^{\mathrm{a}} \mathrm{NW}=$ nonwoven geotextile, $\mathrm{W}=$ woven geotextile, Na-bentonite $=$ sodium bentonite, $\mathrm{NW}(200)=$ nonwoven geotextile $\left(200 \mathrm{~g} / \mathrm{m}^{2}\right)$.

${ }^{\mathrm{b}} \mathrm{PP}=$ polypropylene, $\mathrm{PE}=$ polyethylene, $\mathrm{HDPE}=$ high density polyethylene, $\mathrm{PET}=$ polyester.

${ }^{\mathrm{c}}$ Thickness at $2 \mathrm{kPa}$ for geotextiles and GCLs, at $20 \mathrm{kPa}$ for geocomposites and geomembranes.

${ }^{\mathrm{d}}$ Asperity height $(\mathrm{mm})$ measured through the scanning electron microscope $(\mathrm{SEM})$. GMr2 presents two different textured sides: $\mathrm{s} 1=$ side 1 and s2 $=$ side 2 .

Table 2. Type of soils

\begin{tabular}{|c|c|c|c|c|c|c|c|c|}
\hline \multirow[t]{3}{*}{ Soil } & \multirow[t]{3}{*}{ Grain-size } & \multirow[t]{3}{*}{$w_{\mathrm{L}}{ }^{\mathrm{a}}$} & \multirow[t]{3}{*}{$I_{\mathrm{P}}$} & \multirow[t]{3}{*}{$\operatorname{MP}^{\mathrm{b}}\left(\gamma_{\max } ; w_{\text {opt }}\right)$} & \multicolumn{4}{|c|}{ Direct shear parameters $\left(R^{2}>0.98\right)$} \\
\hline & & & & & \multicolumn{2}{|c|}{ Friction angle $\left({ }^{\circ}\right)$} & \multicolumn{2}{|c|}{ Cohesion $(\mathrm{kPa})$} \\
\hline & & & & & Peak & Residual & Peak & Residual \\
\hline S1 & $90 \%$ fine $10 \%$ coarse & 45 & 21 & $19.2 \mathrm{kN} / \mathrm{m}^{3} ; 12 \%$ & 37 & 34 & 48 & 0 \\
\hline S2 & $85 \%$ fine $15 \%$ coarse & 37 & 17 & $20.6 \mathrm{kN} / \mathrm{m}^{3} ; 8.5 \%$ & 33 & 34 & 9 & 0 \\
\hline S3 & $90 \%$ fine $10 \%$ coarse & 57 & 33.5 & $17.0 \mathrm{kN} / \mathrm{m}^{3} ; 15 \%$ & 25 & 26 & 17.5 & 0 \\
\hline
\end{tabular}

${ }^{\mathrm{a}} w_{\mathrm{L}}=$ liquid limit, $I_{\mathrm{P}}=$ plasticity index.

${ }^{\mathrm{b}} \mathrm{MP}=$ modified proctor compaction was used, $\gamma_{\max }=$ maximum dry density.

$w_{\mathrm{opt}}=$ optimum water content corresponding to saturation degree of $85 \%$.

$1 \mathrm{~mm} / \mathrm{min}$ for soil/GM. These different shear rates were used for the following reasons: on the one hand, the recommendation of the above-mentioned standard (see sections 10.7 and 11.6) was followed. On the other hand, for GT/GM interfaces, the studies of Stark et al. (1996), Triplett and Fox (2001) state that the shear rate does not significantly affect the peak and post-peak strength.

For soil/GM tests, the soil sample was compacted outside the machine applying a static vertical load with a hydraulic press to get the modified Proctor density.

First the normal stress was applied using a rigid loading platen, after $10 \mathrm{~min}$ of consolidation, the lower shear box was moved horizontally at a constant shear rate. The maximum horizontal displacement reached was $50 \mathrm{~mm}$. The shear displacement, shear force and vertical displacement were recorded during the test. The shear force was measured using a suitable dynamometric ring. Two linear variable differential transformers (LVDTs) were used to measure horizontal and vertical displacements.

\section{DIRECT SHEAR TESTS}

\subsection{Geotextile/geomembrane}

\subsubsection{Interface shear strength behaviour}

All interfaces tested present frictional behaviour, which was modelled by Coulomb's equation $\tau=c_{\mathrm{a}}+\sigma_{\mathrm{n}} \cdot \tan (\delta)$, where $\tau$ and $\sigma_{\mathrm{n}}$ are interface shear strength and normal stresses acting on the failure plane, $c_{\mathrm{a}}$ is the interface adhesion and $\delta$ is the interface friction angle. Linear regression of the plot of $\tau$ against $\sigma_{\mathrm{n}}$ was used to identify the best-fit interface shear strength parameters. The shear strength of most interfaces tested in this investigation presented frictional parameters, that is, negligible or null adhesion and important friction angles.

A total of 90 direct shear tests of 18 different GT/GM interfaces (Table 3) were performed under wet conditions. The range of normal stress applied was $25-450 \mathrm{kPa}$. The peak interface shear strength was usually reached at 4-10 $\mathrm{mm}$ and the post-peak strength was obtained at $50 \mathrm{~mm}$. 
Table 3. Geotextile/geomembrane interfaces tested

\begin{tabular}{|c|c|c|c|}
\hline $\begin{array}{l}\text { Geotextile/ } \\
\text { geomembrane } \\
\text { interfaces }\end{array}$ & $\begin{array}{l}\text { Sample } \\
\text { size }(\mathrm{mm})\end{array}$ & $\begin{array}{l}\text { Normal } \\
\text { stress }(\mathrm{kPa})\end{array}$ & $\begin{array}{l}\text { Direct shear test } \\
\text { conditions }\end{array}$ \\
\hline $\begin{array}{l}\text { GT1/GMs } \\
\text { GT1/GMr1 } \\
\text { GT1/GMr2s1 } \\
\text { GT1/GMr2s2 } \\
\text { GT1/GMr3 } \\
\text { GT1/GMr4 } \\
\text { GT2/GMs } \\
\text { GT2/GMr1 } \\
\text { GT2/GMr2s1 } \\
\text { GT2/GMr2s2 } \\
\text { GT2/GMr3 } \\
\text { GT2/GMr4 } \\
\text { GT3/GMs } \\
\text { GT3/GMr1 } \\
\text { GT3/GMr2s1 } \\
\text { GT3/GMr2s2 } \\
\text { GT3/GMr3 } \\
\text { GT3/GMr4 }\end{array}$ & $300 \times 285$ & $\begin{array}{l}25,50, \\
100,300, \\
450\end{array}$ & $\begin{array}{l}\text { Wet: } \\
\text { - hydration time: } \\
\text { geotextile } 24 \mathrm{~h} \text {, } \\
\text { geomembrane } \\
0 \mathrm{~h} \\
\text { consolidation } \\
\text { time: } 10 \mathrm{~min} \\
\text { shear rate: } \\
5 \mathrm{~mm} / \mathrm{min}\end{array}$ \\
\hline
\end{tabular}

Table 4. Geocomposite/geomembrane interfaces tested

\begin{tabular}{|c|c|c|c|}
\hline $\begin{array}{l}\text { Geocomposite/ } \\
\text { geomembrane } \\
\text { interfaces }\end{array}$ & $\begin{array}{l}\text { Sample } \\
\text { size }(\mathrm{mm})\end{array}$ & $\begin{array}{l}\text { Normal } \\
\text { stress (kPa) }\end{array}$ & $\begin{array}{l}\text { Direct shear test } \\
\text { conditions }\end{array}$ \\
\hline $\begin{array}{l}\mathrm{GC1}(200)^{\mathrm{a}} / \mathrm{GMs} \\
\mathrm{GC1}(200) / \mathrm{GMr} 1 \\
\mathrm{GC1}(200) / \\
\mathrm{GMr} 2 \mathrm{~s} 1 \\
\mathrm{GC1}(200) / \\
\mathrm{GMr} 2 \mathrm{~s} 2 \\
\mathrm{GC1}(200) / \mathrm{GMr} 3 \\
\mathrm{GC1}(200) / \mathrm{GMr} 4 \\
\mathrm{GC} 2(140)^{\mathrm{b}} / \mathrm{GMs} \\
\mathrm{GC} 2(140) / \mathrm{GMr} 1 \\
\mathrm{GC} 2(140) / \\
\mathrm{GMr} 2 \mathrm{~s} 1 \\
\mathrm{GC} 2(140) / \\
\mathrm{GMr} 2 \mathrm{~s} 2 \\
\mathrm{GC} 2(140) / \mathrm{GMr} 3 \\
\mathrm{GC} 2(140) / \mathrm{GMr} 4\end{array}$ & $300 \times 285$ & $25,50,100$ & $\begin{array}{l}\text { Dry: } \\
\text { consolidation } \\
\text { time: } 10 \mathrm{~min} \\
\text { shear rate: } \\
5 \mathrm{~mm} / \mathrm{min}\end{array}$ \\
\hline
\end{tabular}

${ }^{\mathrm{a}} \mathrm{GC1}(200)=\mathrm{GC} 1$ was tested by the side of the $\mathrm{NW}$ of $200 \mathrm{gr} / \mathrm{m}^{2}$.

${ }^{\mathrm{b}} \mathrm{GC} 2(140)=\mathrm{GC} 2$ was tested by the side of the NW of $140 \mathrm{gr} / \mathrm{m}^{2}$.
Table 5. Soil/geomembrane interfaces tested

\begin{tabular}{|c|c|c|c|}
\hline $\begin{array}{l}\text { Geotextile/ } \\
\text { geomembrane } \\
\text { interfaces }\end{array}$ & $\begin{array}{l}\text { Sample } \\
\text { size }(\mathrm{mm})\end{array}$ & $\begin{array}{l}\text { Normal } \\
\text { stress }(\mathrm{kPa})\end{array}$ & $\begin{array}{l}\text { Direct shear test } \\
\text { conditions }\end{array}$ \\
\hline $\begin{array}{l}\text { S1/GMs } \\
\text { S1/GMr1 } \\
\text { S1/GMr2s1 } \\
\text { S1/GMr3 } \\
\text { S2/GMs } \\
\text { S2/GMr1 } \\
\text { S2/GMr2s1 } \\
\text { S2/GMr3 } \\
\text { S3/GMs } \\
\text { S3/GMr1 } \\
\text { S3/GMr3 }\end{array}$ & $200 \times 200$ & $\begin{array}{l}100,300, \\
500\end{array}$ & \begin{tabular}{|l} 
Dry: \\
static \\
compaction of \\
soil off shear \\
machine \\
consolidation \\
time: 10 min. \\
shear rate: \\
$1 \mathrm{~mm} / \mathrm{min}$
\end{tabular} \\
\hline
\end{tabular}

Figure 2a presents graphs of typical interface shear strength plotted against shear displacement for a nonwoven geotextile/textured geomembrane interface (GT1/ GMr2s1). Strain-softening behaviour can be observed (Byrne 1994; Stark et al. 1996; Jones and Dixon 1998) and the higher the normal stress, the higher the strainsoftening behaviour (Bacas et al. 2011).

Approximately $60 \%$ of the tests revealed non-linear failure envelopes and 40\% linear envelopes. Figure $2 \mathrm{~b}$ shows non-linear peak and post-peak failure envelopes (continuous lines). However, the straight envelopes passing through the origin (dashed lines) with peak and post-peak friction angles of $23^{\circ}$ and $10^{\circ}$ also show a good fit $\left(R^{2}>0.9\right)$.

In agreement with Giroud et al. (1990), Koutsourais et al. (1991), Stark et al. (1996), Hebeler et al. (2005), McCartney et al. (2009) and Kim and Frost (2011), the interaction mechanism during the shear of geotextile/ textured geomembrane presented two main components: one was the interlocking (hook and loop) between the individual filaments and the geomembrane roughness and the other was the friction between the materials. Figure 3 illustrates how these mechanisms developed at a superficial level $(<50 \mathrm{kPa})$ or at a geotextile matrix level, which depended on the normal stress.

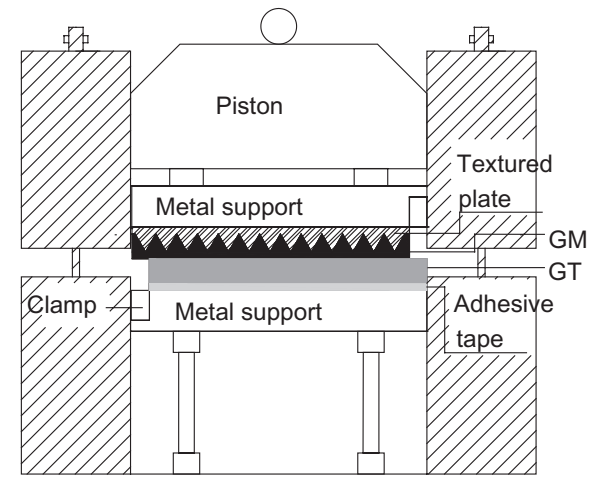

(a)

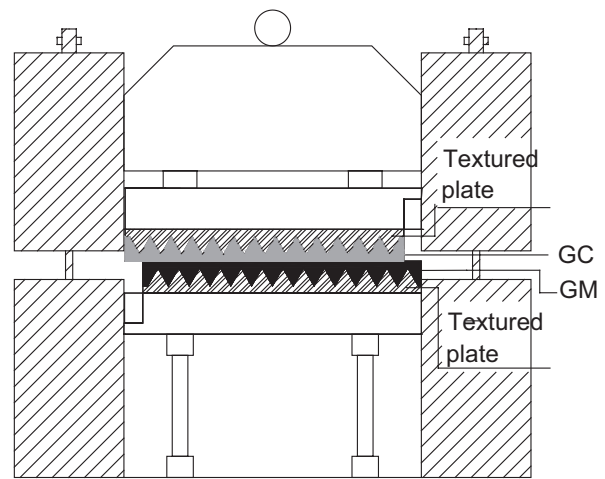

(b)

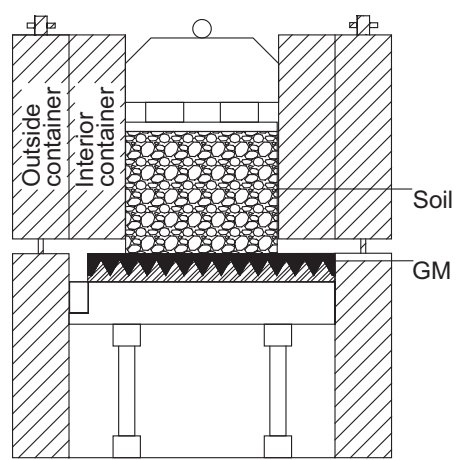

(c)

Figure 1. Sketch of large direct shear test: (a) GT/GM, (b) GC/GM and (c) Soil/GM

Geosynthetics International, 2015, 22, No. 5 


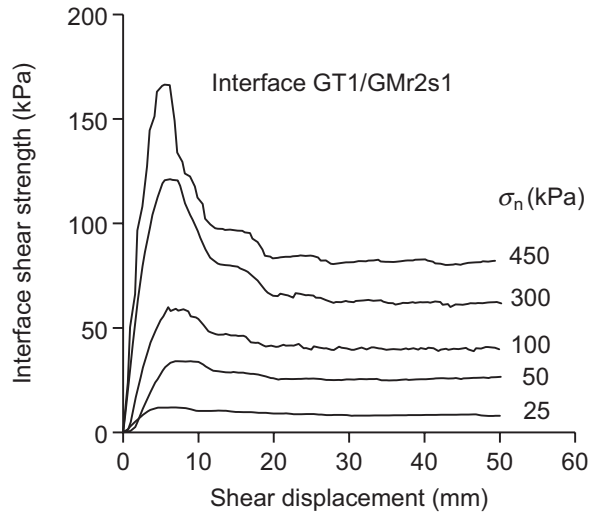

(a)

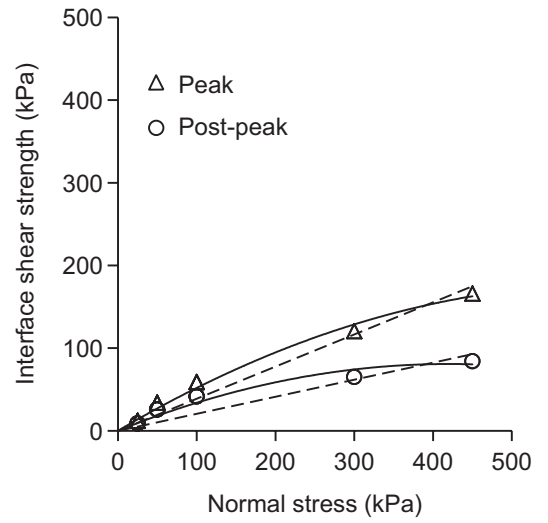

(b)

Figure 2. Interface needle-punched GT/textured GM: (a) interface shear strength plotted against shear displacement curves; (b) peak and post-peak failure envelopes

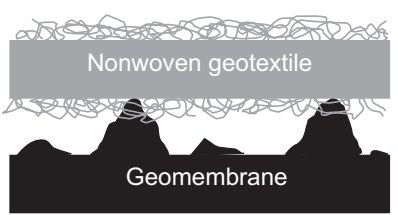

(a)

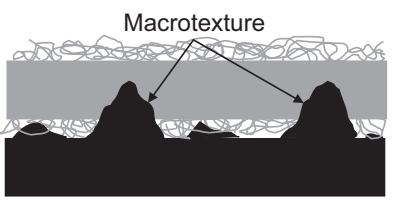

(b)

Figure 3. Interaction mechanisms between NW GT and textured GM at different normal stresses (cross shear direction section): (a) at low normal stress; (b) at high normal stress (after Hebeler et al. 2005)

\subsubsection{Influence of geomembrane roughness}

Figure 4 presents graphs of the interface friction angles plotted against asperity height $(\mathrm{mm})$, where the following aspects were observed: The smaller values belonged to the smooth geomembrane (GMs) and the interface shear strength was supplied by the friction mechanism; hence, the GT/GMs interfaces presented similar peak and post-peak friction angles.

The interlocking mechanism was directly affected by the roughness, increasing the peak interface shear strength as well as causing strain softening behaviour. Normally, the higher the asperity height and interlocking, the higher the peak interface shear strength (Ivy 2003; McCartney et al. 2005). Hence, GMr2s1 and GMr3 with asperity heights larger than $1 \mathrm{~mm}$ (Table 1) showed the greatest

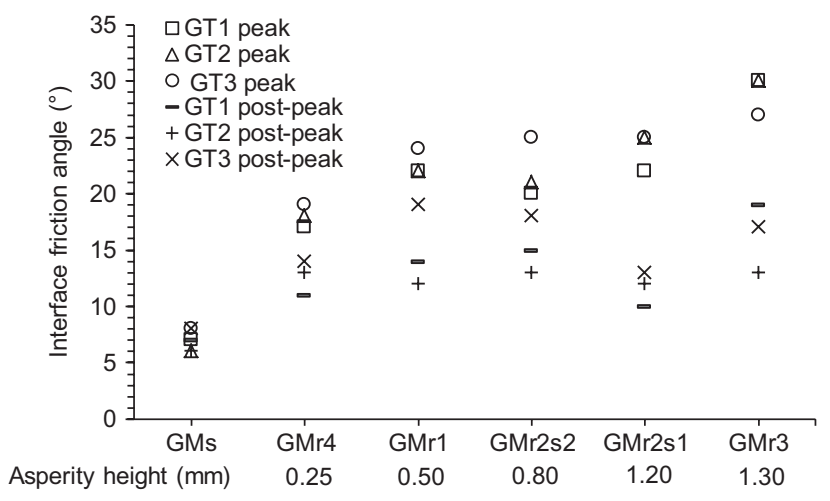

Figure 4. Interface friction angles of GT/GM interfaces peak values. Similarly, GMr4 had the smallest asperity height and presented the smallest peak frictional angles. Furthermore, the interlocking increased with increasing normal stress (Bacas et al. 2011).

The post-peak values did not show a clear trend related to the size of the asperity, but show dependency on the type of geotextile (McCartney et al. 2005).

\subsubsection{Influence of geotextile fibres}

Figure 5 shows interface shear strength plotted against shear displacement curves at $50 \mathrm{kPa}$ for the needlepunched geotextiles, GT1 and GT2. They were made of needle-punched monofilament and staple fibres, respectively (Table 1). It can be observed that the length of the fibres greatly affected the interface shear strength at low normal stress. GT2 presented the smaller interface shear strength values for both geomembranes, GMr1 and GMr3, whose macrotexture is smaller and greater than $1 \mathrm{~mm}$, respectively. Thus, at a superficial level, the staple fibres of the GT2 did not develop an interlocking mechanism as strong as the monofilament of the GT1 did.

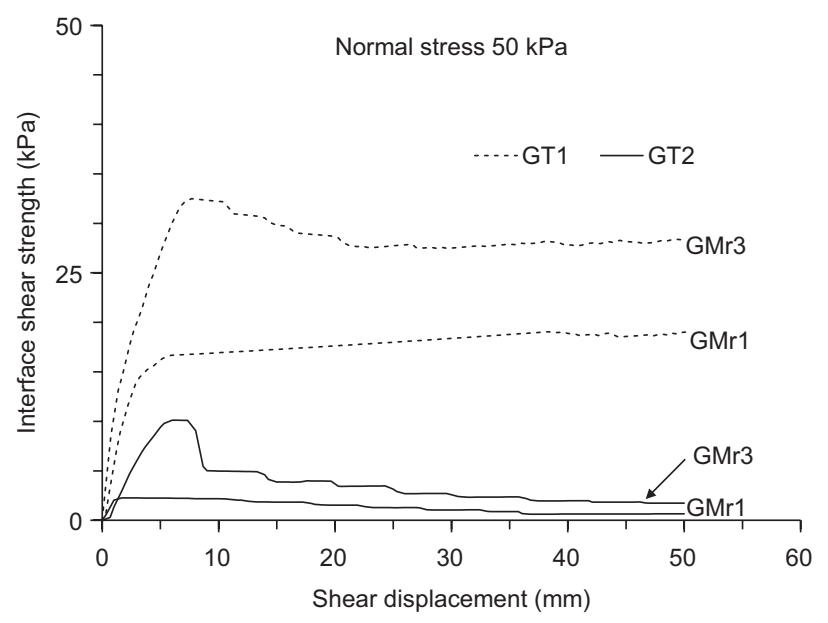

Figure 5. Interface shear strength plotted against shear displacement at low normal stress for needle-punched GT/textured GM interfaces 
On the other hand, the influence of the manufacture of the geotextiles can be observed by comparing the nonwoven monofilament geotextiles GT1 and GT3 in Figure 4 . The former is made by needle-punching and the latter is made by a heat bonding system. Figure 6 shows microscope pictures of these geotextiles. GT1 presents looser filaments and greater gaps than GT3, which shows higher interlocking, leading to higher interface shear strength.

Finally, the post-peak values seem to depend on the type of geotextile to some extent. Figure 4 shows that GT3 presented the largest post-peak values except for GMr3, because its heat-bonded monofilaments were stretched and very tangled during the shear, causing a higher resistance as the geomembrane brushed against the geotextile. GT2 on the other hand presented most of the lowest post-peak values because its staple fibres were stretched and brushed most easily.

One conclusion from these analyses is that the manufacturing process of the geotextile influences both the peak and the post-peak interface shear strength. If the geomembrane roughness is irregular and dense the use of heat-bonded monofilaments is recommended, because the interlocking mechanism has a big influence on interface shear strength. If, however, the roughness is regular and uniform then the use of needle-punched filaments is recommended, especially for high normal stress levels.
Finally, for cover systems of landfills subjected to low ranges of normal stresses, the use of monofilament rather that staple fibres are recommend, because the former mobilises the interlocking mechanism at lower normal stresses better than the latter.

\subsection{Drainage geocomposite/geomembrane}

\subsubsection{Interface shear strength behaviour}

The drainage GC/GM interfaces were tested with normal stress ranging from 25 to $100 \mathrm{kPa}$, which simulate the upper range of low normal stresses that typical cap and liner systems are subjected to. A total of 36 direct shear tests of 12 different drainage GC/GM interfaces (Table 4) were carried out under dry conditions. In addition, eight tests of geocomposites alone ( $\mathrm{GC} 1$ and $\mathrm{GC} 2$ ) were performed in dry conditions. The peak interface shear strength was usually reached at $3-8 \mathrm{~mm}$ in line with Stark et al. (1996), the post-peak strength was reached at $50 \mathrm{~mm}$.

Figure 7a presents curves of typical interface shear strength plotted against shear displacement for drainage of geocomposite/textured geomembrane interfaces, GC2 (140)/GMr3. The asperity height of GMr3 was $>1 \mathrm{~mm}$. The drainage geocomposite $\mathrm{GC} 2$ had two needlepunched geotextiles, 120 and $140 \mathrm{~g} / \mathrm{m}^{2}$ (side tested), thermally bonded to a geonet (Table 1). These curves show that the reduction in shear stress at displacements beyond peak led to the typical strain softening behaviour

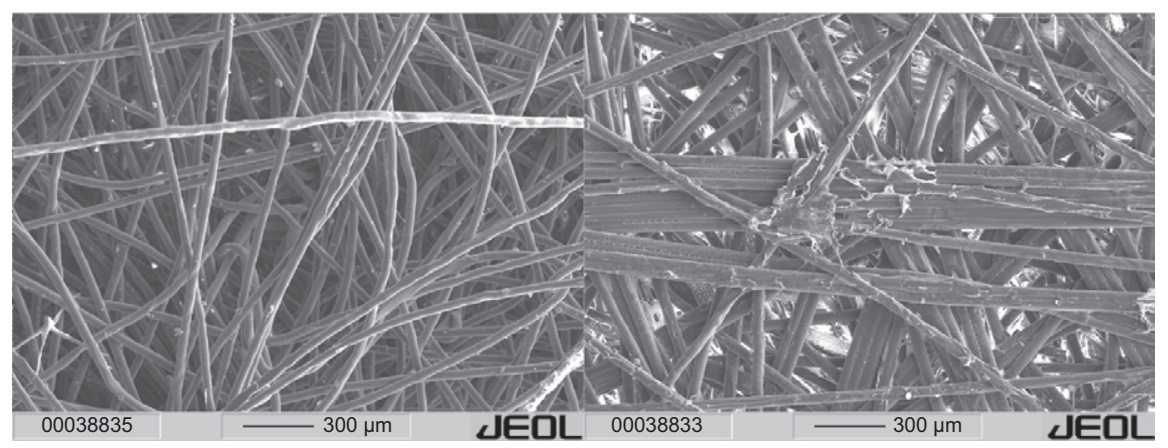

(a)

(b)

Figure 6. Scanning electron microscope (SEM) images of geotextiles: (a) GT1; (b) GT3

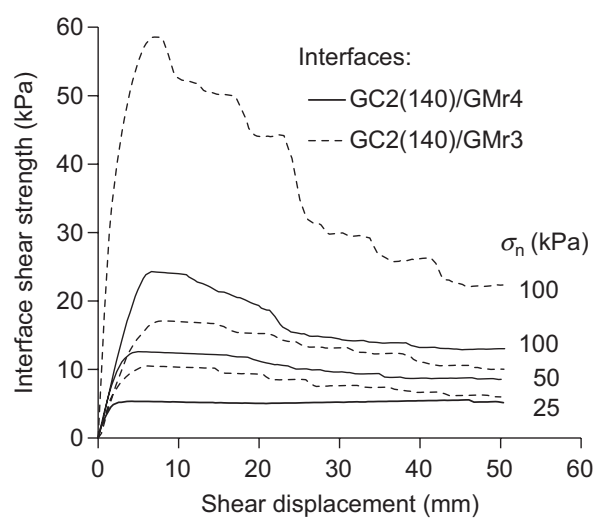

(a)

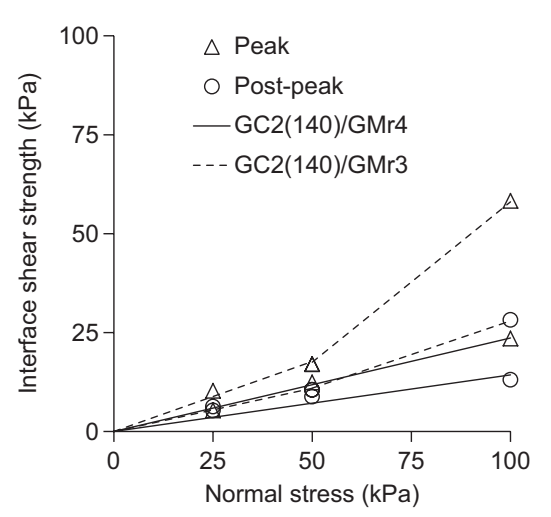

(b)

Figure 7. Interface drainage geocomposite/textured geomembrane: (a) interface shear strength plotted against shear displacement curves; (b) peak and post-peak failure envelopes 
(Byrne 1994; Stark et al. 1996). The curve of $100 \mathrm{kPa}$ presents a peak interface shear strength larger than the others. Although the data are limited, the failure envelope tends to be bilinear (Figure 7b), with the inflection point at normal stress of $50 \mathrm{kPa}$, indicating that beyond the normal stress of $50 \mathrm{kPa}$, the interaction mechanisms changed.

The analysis of the interface shear strength curves as well as the samples after testing resulted in the interaction mechanisms presented in Figure 8. As was the case for GT/GM interfaces, the interaction mechanisms depended on the normal stress applied. At low normal stress the interaction was mainly between the geotextile and the geomembrane, and therefore similar to the GT/GM interfaces described earlier. Figure 8a displays the interlocking (hook and loop) between geotextile filaments and geomembrane roughness and the friction mechanisms. Thus, the geonet does not significantly affect interface shear strength.

As normal stress increases, the geotextiles are compressed around the strands of the geonet, which is embedded into the geomembrane, as shown in Figure 8b. Therefore, the shear behaviour is frictional, similar to the geonet/geomembrane interfaces (Koutsourais et al. 1991; Byrne et al. 1992; Bergado et al. 2006), the interlocking mechanism hardly makes a difference. The friction takes place between the geonet strands and the geomembrane roughness (Giroud et al. 1990). The geonet aids the damage or removal of the roughness from the geomembrane as Stark et al. (1996) also pointed out.

The failure plane occurred between the geotextile of the drainage geocomposite and the geomembrane. However,

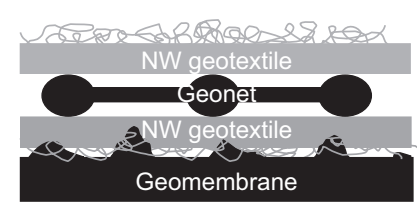

(a)

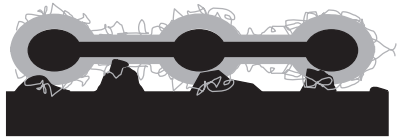

(b)
Figure 8. Interaction mechanisms between drainage geocomposite and textured GM (cross shear direction section): (a) at low normal stress; (b) at high normal stress for $\mathrm{GC} / \mathrm{GMr} 3$ interfaces at normal stress of $100 \mathrm{kPa}$ the failure plane was inside the drainage geocomposite, between the geonet and the geotextile. Due to this fact, $\mathrm{GC} 1$ and $\mathrm{GC} 2$ were tested alone. The peak secant friction angles at $100 \mathrm{kPa}$ were $28^{\circ}$ and $26^{\circ}$, respectively. These values are smaller than the peak secant friction angles of $\mathrm{GCl}(200) / \mathrm{GMr} 3$ and $\mathrm{GC} 2(140) / \mathrm{GMr} 3,32^{\circ}$ and $30^{\circ}$, confirming the internal geocomposite weakness plane.

\subsubsection{Influence of geomembrane roughness}

Figure 7 presents the results of two types of interfaces: $\mathrm{GC} 2(140) / \mathrm{GMr} 4$ and GC2(140)/GMr3. The asperity height of GMr4 was $<1 \mathrm{~mm}$ and GMr3 was $>1 \mathrm{~mm}$. GMr3 exhibited higher interface shear strength than GMr4. The failure envelopes of GMr3 were bilinear but $\mathrm{GMr} 4$ had a linear failure envelope for the normal stress range tested. This was due to the fact that geomembranes with asperities smaller than $1 \mathrm{~mm}$ presented the inflexion point at a higher normal stress $(>100 \mathrm{kPa})$ than geomembranes with asperities larger than $1 \mathrm{~mm}(50 \mathrm{kPa})$, as can be observed in Figure 9b. GMr1, GMr2s2 and GMr4 present similar interface shear strengths and linear envelopes, increasing the interface shear strength proportionally to the normal stress. However, GMr2 and GMr3 do not; they exhibit bilinear failure envelopes.

Figure $9 \mathrm{a}$ presents the friction angles of the drainage GC/GM interfaces tested plotted against asperity height. These friction angles were within the range of the values presented by Stark et al. (1996). The results prove that the geomembrane roughness increased the interface shear strength: the higher the asperity height, the higher the shear strength. This fact is more noticeable when the roughness was larger than $1 \mathrm{~mm}$.

\subsection{Soil/geomembrane}

\subsubsection{Interface shear strength behaviour}

The soil/GM interfaces were tested at normal stress of 100 , 300 and $500 \mathrm{kPa}$, simulating the range of normal stresses that typical liner systems are subject to. A total of 33 direct shear tests of 11 soil/GM interfaces were performed in dry conditions (Table 5). The soil samples were $200 \mathrm{~mm}$ long, $200 \mathrm{~mm}$ wide and $50 \mathrm{~mm}$ high. They were compacted outside the direct shear machine to get the

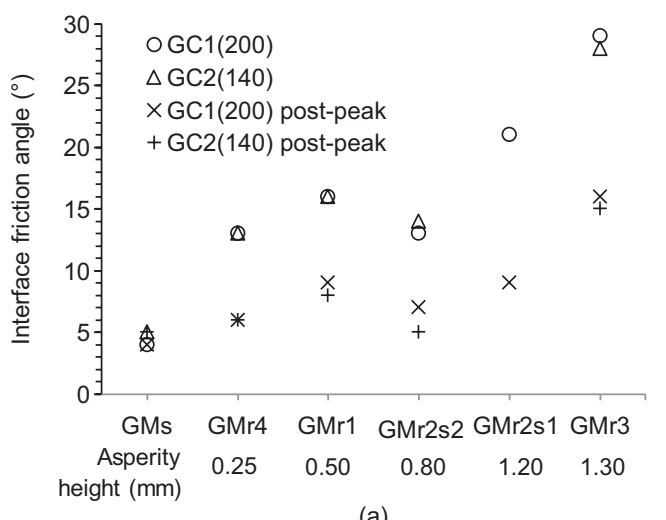

(a)

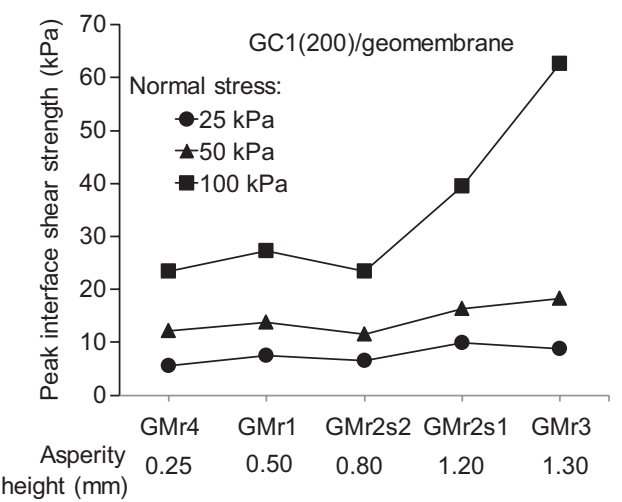

(b)

Figure 9. (a) Interface friction angle of drainage geocomposite/geomembrane; (b) peak interface shear strength plotted against asperity height 
modified Proctor density and the optimum water content (Table 2). However, in real conditions, the soil was directly compacted on the geosynthetic, which can affect to the results at low normal stress.

The peak interface shear strength was usually reached at 3-8 $\mathrm{mm}$ (Stark and Poeppel 1994), the post-peak strength was measured at $50 \mathrm{~mm}$.

Figure 10a presents the typical interface shear strength - shear displacement curves for the interfaces $\mathrm{S} 1 / \mathrm{GMr} 3$ and S1/GMr1. The interface shear strength curves present strain-softening behaviour, as described in previous interfaces (GT/GM and drainage GC/GM). The interface shear strength reaches its peak when the asperities move the soil over them. Then, the strength goes down because the remoulded soil resists less. Figure 10b shows the straight failure envelopes for high normal stresses. The peak and post-peak friction angles were $29^{\circ}$ and $20^{\circ}$ for $\mathrm{S} 1 / \mathrm{GMr} 3,31^{\circ}$ and $27^{\circ}$ for $\mathrm{S} 1 / \mathrm{GMr} 1$.

All test results analysed and the observation of the samples after testing show the interaction mechanisms developed during shearing. These interaction mechanisms followed the same rules as GT/GM and drainage GC/GM interfaces. Figure 11 illustrates different behaviours at low and high normal stress. At the low normal stress tested, $100 \mathrm{kPa}$, the asperities slightly embedded into the soil. Thus, the interface shear strength was mainly supplied by the sliding between asperities and the soil at a superficial level. However, it is noteworthy that this behaviour may be affected by the way the soil was compacted. As the normal stress increased $(>100 \mathrm{kPa})$, the soil was entirely embedded between the asperities, and interface shear strength came from a friction mechanism developed in two ways: one was the internal shear strength of the soil itself placed above the geomembrane and the other was the friction between the asperities and the soil, as indicated in Figure 11b, that is, the sliding and ploughing effect reported by Zettler et al. (2000).

\subsubsection{Influence of geomembrane roughness}

Figure 10 shows the results of the interfaces $\mathrm{S} 1 / \mathrm{GMr} 1$ and S1/GMr3. GMr1 has an irregular heavily textured surface smaller than $1 \mathrm{~mm}$. GMr3 has regular asperities larger than $1 \mathrm{~mm}$. GMr1 reached greater interface shear strength than GMr3. The roughness of GMr1 was almost entirely embedded into the soil, which caused the interface shear strength to be mainly supplied by the internal shear strength of the soil itself. The shear plane was inside the soil as shown in Figure 12a (Koerner et al. 1986; Mitchell and Mitchell 1992; Orman 1994). However, the roughness of GMr3 led to a ploughing effect, mobilising the internal shear strength of the soil and the friction of the soil-roughness contacts, which remoulded the soil and resulted in smaller post-peak values (Zettler et al. 2000). In this case, the shear plane was between the soil and the geomembrane as shown in Figure 12b.

Figure 13 presents the friction angles of the soil/GM interfaces tested, observing that evidently, the smooth geomembrane offered the smallest interface shear strength. The peak friction values were between $6^{\circ}$ and $11^{\circ}$ and the post-peak ones between $3^{\circ}$ and $8^{\circ}$. These values are in line with the data shown by Seed and Boulanger (1991), Koerner et al. (1986), Stark and

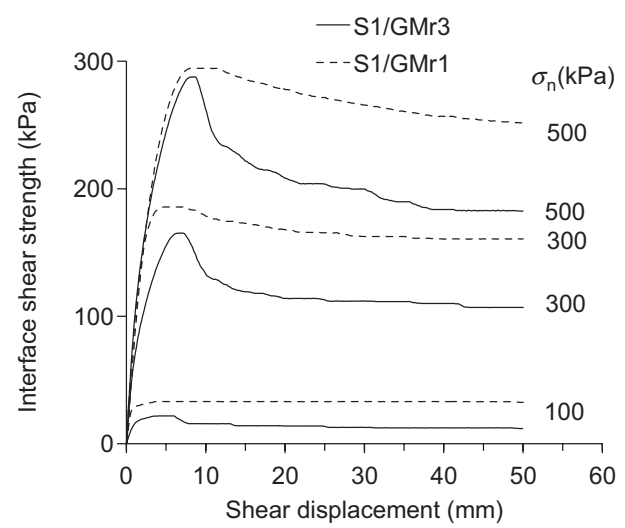

(a)

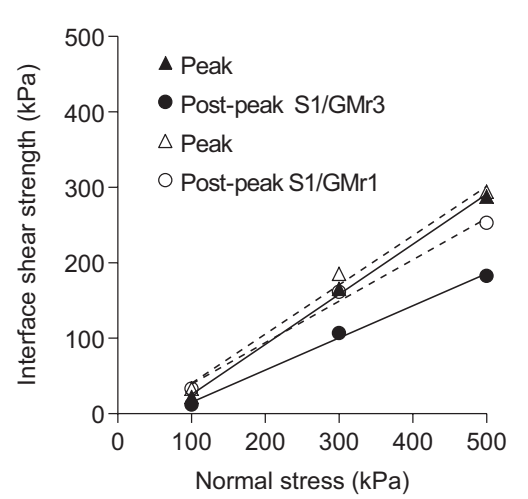

(b)

Figure 10. Interfaces S1/GMr3 and S1/GMr1: (a) interface shear strength shear plotted against displacement curves; (b) peak and post-peak failure envelopes

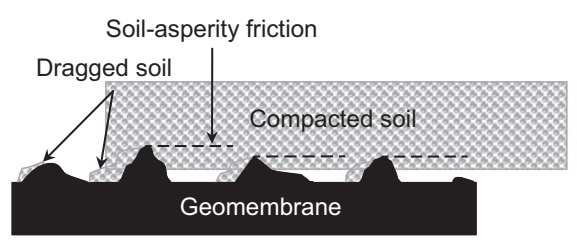

(a)

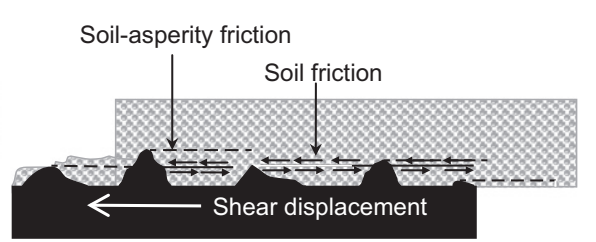

(b)

Figure 11. Interaction mechanisms between the soil and the textured geomembrane (shear direction section): (a) at low normal stress; (b) at high normal stress 


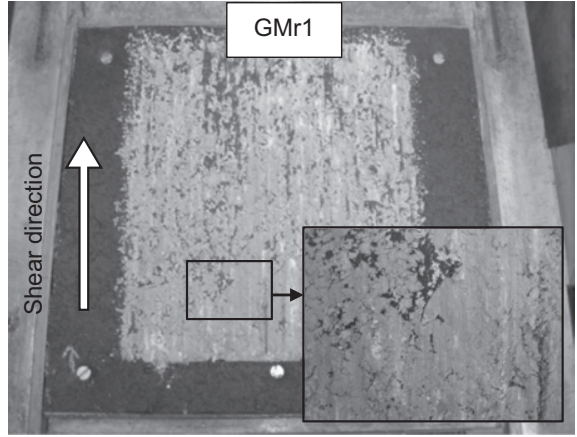

(a)

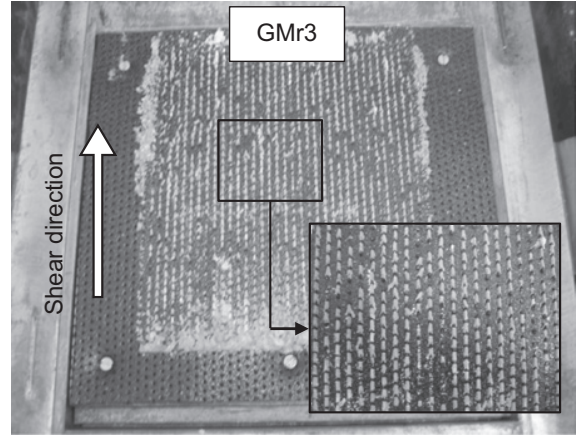

(b)

Figure 12. GMr1 and GMr3 samples after testing with $\mathrm{S} 1$ at normal stress of $500 \mathrm{kPa}$

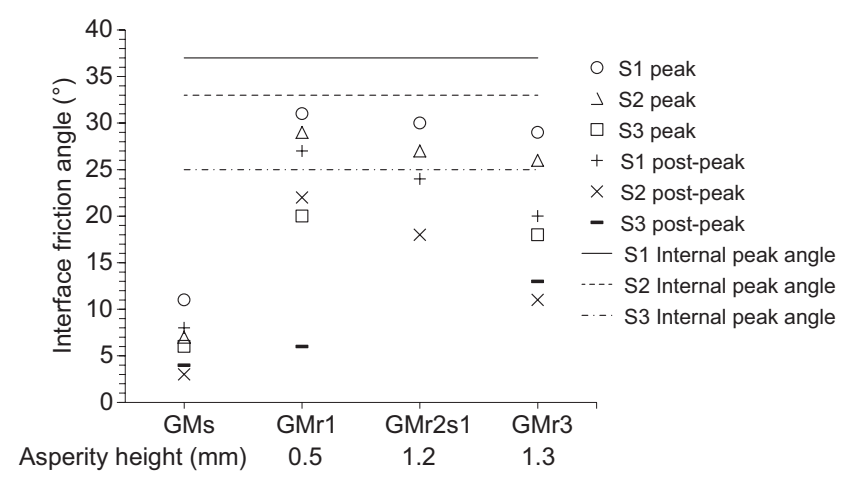

Figure 13. Interface friction angles of soil/GM interfaces and compacted soils

Poeppel (1994) and Bergado et al. (2006). In this case, the post-peak strength was caused by the polishing of the smooth geomembrane during the shear and the damage on its surface. This damage was caused by the friction of coarser particles within the clayed soil (Zettler et al. 2000; Sharma et al. 2007). These facts were observed in the visual inspection of the samples after testing.

The peak friction angles of the compacted soil/textured geomembrane interfaces were between $18^{\circ}$ and $32^{\circ}$, in line with data from Mitchell and Mitchell (1992). The post-peak angles were between $6^{\circ}$ and $27^{\circ}$. GMr1 usually yielded the largest peak values, because most of the friction was provided by the soil itself. GMr2s1 presented slightly larger values than GMr3, because the asperity of GMr2s1 was less dense (4 units $/ \mathrm{cm}^{2}$ ) than that of GMr3 $\left(9\right.$ units $\left./ \mathrm{cm}^{2}\right)$. This means that there was more soil between the asperities of GMr2s1 than between that of GMr3, and hence the former moved more soil friction, causing larger peak values.

\subsubsection{Influence of type of soil}

Small direct shear tests were carried out with the different soils, S1, S2 and S3 to analyse their effects on the interfaces. The sample dimensions were $60 \mathrm{~mm}$ long $\times$ $60 \mathrm{~mm}$ wide $\times 29 \mathrm{~mm}$ height. The normal stresses applied were 100,200 and $300 \mathrm{kPa}$ and the constant shear rate was $0.006 \mathrm{~mm} / \mathrm{min}$. The soil samples were prepared by modified Proctor density and water content (Table 2).
Figure 13 shows that the soil S1 presented the largest peak interface friction angles, $37^{\circ}$. Furthermore, these results show that the largest interface friction angles belonged to $\mathrm{S} 1$ /geomembranes, whose peak values were between $29^{\circ}$ and $32^{\circ}$ and post-peak values were between $20^{\circ}$ and $27^{\circ}$. Note that these values did not exceed the angles of internal shear strength of the soil S1 itself (Koerner et al. 1986; Koutsourais et al. 1991; Mitchell and Mitchell 1992; Stark and Poeppel 1994; Bergado et al. 2006).

The soil S3 $\left(I_{\mathrm{p}}=34\right)$, which was more clayed than the soils $\mathrm{S} 1\left(I_{\mathrm{p}}=21\right)$ and $\mathrm{S} 2\left(I_{\mathrm{p}}=17\right)$, presented the lowest peak angle of friction, $25^{\circ}$, as well as the lowest peak friction angles of $\mathrm{S} 3 /$ geomembrane interfaces, $18^{\circ}$ to $20^{\circ}$, and the lowest post-peak values, $6^{\circ}$ to $13^{\circ}$. These findings prove that the internal shear strength of soil was the main interaction mechanism supplying interface shear strength at high normal stress, as also pointed out by Koerner et al. (1986) and Mitchell and Mitchell (1992).

\subsection{Comparison of peak friction angles}

Figure 14 compares the peak interface friction angles, which were from lowest to highest: drainage in the order GC/GM, GT/GM and soil/GM.

An exception to this were the interfaces formed with the geomembrane GMr3, which showed similar values with the geotextiles and the drainage geocomposites tested and the compacted soils S1 and S2. The only exception was the

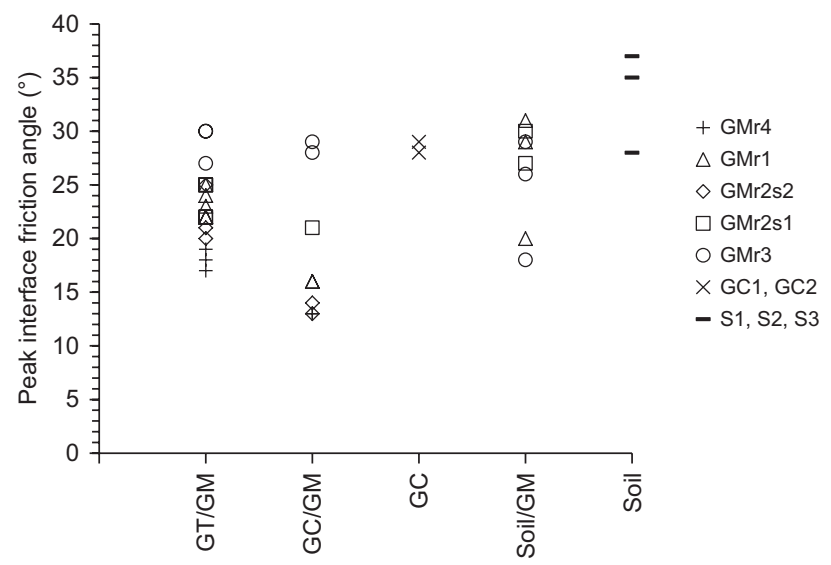

Figure 14. Comparison of peak friction angles between interfaces 
compacted soil S3 that presented the lowest values due to its larger plasticity index.

\section{CONCLUSIONS}

Large direct shear tests were conducted on three critical interfaces typically used for lined containment facilities: GT/GM, drainage GC/GM and soil/GM. The following main conclusions are derived from this study.

(a) The interface shear interaction mechanisms depend on the normal stress, for GT/GM interfaces, the interlocking and friction mechanisms take place at a superficial level at low normal stress $(<50 \mathrm{kPa})$ and at a matrix level at high normal stress $(>50 \mathrm{kPa})$. For drainage GC/GM interfaces, the interlocking and friction mechanism appeared at low normal stress $(<50 \mathrm{kPa})$. However, only the friction mechanism appears at high normal stress $(>50 \mathrm{kPa})$. For soil/ GM interfaces, the friction mechanism appeared at low normal stress $(<100 \mathrm{kPa})$ and internal soil friction at high normal stress $(>100 \mathrm{kPa})$.

(b) For GT/GM interfaces, the peak interface shear strength mainly depended on the roughness of the geomembrane. Whereas post-peak interface shear strength appeared to depend on the type of geotextile. Usually the geotextiles made with staple fibres presented smaller post-peak values than monofilaments.

(c) If the roughness of the geomembrane is irregular and dense it is recommended that nonwoven geotextile made of monofilaments was used, because it develops a larger interlocking mechanism causing the interface shear strength to increase.

(d) If the roughness of the geomembrane is regular and evenly spread it is recommended to use the nonwoven geotextile with needle-punched filaments, especially for high normal stresses.

(e) For cover systems of landfills subject to low normal stresses, it is recommend that monofilaments be used rather than staple fibres, since the former mobilises the interlocking mechanism at lower normal stresses.

(f) For drainage GC/GM interfaces, the shape of the interface shear strength failure envelope depends on the asperity height of the textured geomembrane. If the asperity is smaller than $1 \mathrm{~mm}$ the failure envelope is linear, but if the asperity is larger than $1 \mathrm{~mm}$ it is bilinear.

(g) The comparison of peak friction angles of the geosynthetic interfaces tested usually showed the following interfaces from most critical to least critical: drainage GC/GM, GT/GM and soil/GM.

\section{ACKNOWLEDGEMENTS}

This work was derived from an extensive research project sponsored by the Company Ferrovial S.A. (Spain) and conducted by the Geotechnical Group at the Civil Engineering School at University of Cantabria (Spain).
The facilities provided for this research project are gratefully acknowledged. Moreover, the authors are grateful to Deutscher Akademischer Austausch Dienst (DAAD, Germany) for the research fellowship received, as well as the facilities provided by the Chair for Rock Mechanics at the Geotechnical Institute at the Technical University Bergakademie Freiberg, Germany.

\section{NOTATION}

Basic SI units are given in parentheses.

$c_{\mathrm{a}}$ adhesion of interface $(\mathrm{Pa})$

$I_{\mathrm{p}}$ plasticity index (dimensionless)

$\delta$ interface friction angle (degrees)

$\sigma_{\mathrm{n}} \quad$ normal stress $(\mathrm{Pa})$

$\tau$ interface shear strength $(\mathrm{Pa})$

\section{ABBREVIATIONS}

$\begin{aligned} \text { GT } & \text { geotextile } \\ \text { GM } & \text { geomembrane } \\ \text { GC } & \text { drainage geocomposite } \\ \text { GT1, GT2, GT3 } & \text { geotextile type 1, 2, 3 } \\ \text { GMr1, GMr3, } & \text { geomembrane type 1,3,4 } \\ \text { GMr4 } & \\ \text { GMr2s1, GMr2s2 } & \text { geomembrane type 2 side 1, side 2 } \\ \text { GC1, GC2 } & \text { drainage geocomposite type 1,2 } \\ \text { S1, S2, S3 } & \text { soil type 1, 2, 3 }\end{aligned}$

\section{REFERENCES}

ASTM D5321 Standard Test Method for Determining the Coefficient of Soil and Geosynthetic or Geosynthetic and Geosynthetic Friction by Direct Shear Method. ASTM International, West Conshohocken, PA, USA.

Bacas, B. M., Konietzky, H., Cañizal, J. \& Sagaseta, C. (2011). A new constitutive model for textured gemembrane/geotextile interfaces. Geotextiles and Geomembranes, 29, No. 2, 137-148.

Bergado, D. T., Ramana, G. V., Sia, H. I. \& Varun, R. (2006). Evaluation of interface shear strength of composite liner system and stability analysis for a landfill lining system in Thailand. Geotextiles and Geomembranes, 24, No. 6, 371-393.

Brachman, R. W. I. \& Sabir, A. (2013). Long-term assessment of a layered-geotextile protection layer for geomembranes. Journal of Geotechnical and Geoenvironmental Engineering, 139, No. 5, $752-764$.

Briançon, L., Girard, H. \& Gourc, J. P. (2011). A new procedure for measuring geosynthetic friction with an inclined plane. Geotextiles and Geomembranes, 29, No. 5, 472-482.

Byrne, R. J. (1994). Design issues with strain-softening interfaces in landfill liners. Proceedings of Waste Technology '94, Charleston, SC, USA, Sesion 4, Paper 4.

Byrne, R. J., Kendall, J. \& Brown, S. (1992). Cause and mechanism of failure, Kettleman Hills Landfill B-19, Phase IA. In Stability of Slopes and Embankments II, Seed, R. B. \& Boulanger, R. W., Editors, American Society of Civil Engineers, New York, NY, USA, Geotechnical Special Publication no. 31, vol. 2, pp. $1188-1215$.

Eid, H. T. (2011). Shear strength of geosynthetic composite systems for design of landfill liner and cover slopes. Geotextiles and Geomembranes, 29, No. 3, 335-344. 
Eid, H. T., Stark, T. D. \& Doerfler, C. K. (1999). Effect of shear displacement rate on internal shear strength of a reinforced geosynthetic clay liner. Geosynthetics International, 6, No. 3, 219-239.

Fox, P. J. \& Kim, R. H. (2008). Effect of progressive failure on measured shear strength of geomembrane/GCL interface. Journal of Geotechnical and Geoenvironmental Engineering, 134, No. 4, 459-469.

Fox, P. J. \& Ross, J. D. (2011). Relationship between NP GCL internal and HDPE GMX/NP GCL interface shear strengths. Journal of Geotechnical and Geoenvironmental Engineering, 137, No. 8, 743-753.

Fox, P. J. \& Stark, T. D. (2015). State-of-the-art report: GCL shear strength and its measurement - ten-year update. Geosynthetics International, 22, No. 1, 3-47.

Fox, P. J., Rowland, M. G., Scheithe, J. R., Davis, K. L., Supple, M. R. \& Crow, C. C. (1997). Design and evaluation of a large direct shear machine for geosynthetic clay liners. Geotechnical Testing Journal, 20, No. 3, 279-288.

Fox, P. J., Rowland, M. G. \& Scheithe, J. R. (1998). Internal shear strength of three geosynthtic clay liners. Journal of Geotechnical and Geoenvironmental Engineering, 124, No. 10, 933-944.

Fox, P. J., Ross, J. D., Sura, J. M. \& Thiel, R. S. (2011). Geomembrane damage due to static and cyclic shearing over compacted gravelly sand. Geosynthetics International, 18, No. 5, 272-279.

Gilbert, R. B. \& Byrne, R. J. (1996). Strain-softening behavior of waste containment system interfaces. Geosynthetics International, 3, No. 2, 181-202.

Giroud, J. P. \& Darrasse, J. (1993). Hyperbolic expression for soil-geosynthetics or geosynthetics-geosynthetic interface shear strength. Geotextiles and Geomembranes, 12, No. 3, 275-286.

Giroud, J. P., Swan, R. H., Richer, P. J. \& Spooner, P. R. (1990). Geosynthetic landfill cap: Laboratory and field tests, design and construction. In Proceedings of the 4th International Conference on Geotextiles, Geomembranes and Related Products, Den Hoedt, G., Editor, Balkema, Rotterdam, the Netherlands, pp. 493-498.

Hebeler, G. L., Frost, J. D. \& Myers, A. T. (2005). Quantifying hook and loop interaction in textured geomembrane-geotextile systems. Geotextiles and Geomembranes, 23, No. 1, 77-105.

Ivy, N. (2003). Asperity height variability and effects. GFR, 21, October-November, 28-29.

Jones, D. R. V. \& Dixon, N. (1998). Shear strength properties of geomembrane/geotextile interfaces. Geotextiles and Geomembranes, 16, No. 1, 45-71

Kim, D. \& Frost, J. D. (2011). Effect of geotextile constraint on geotextile/geomembrane interface shear behavior. Geosynthetics International, 18, No. 3, 104-123.

Koerner, R. M., Martin, J. P. \& Koerner, G. R. (1986). Shear strength parameters between geomembranes and cohesive soils. Geotextiles and Geomembranes, 4, No. 1, 21-30.

Koutsourais, M. M., Sprague, C. J. \& Pucetas, R. C. (1991). Interfacial friction study of cap and liner components for landfill design. Geotextiles and Geomembranes, 10, No. 5-6, 531-548.

Liu, H. \& Martinez, J. (2014). Creep behavior of sand-geomembrane interfaces. Geosynthetics International, 21, No. 1, 83-88.

McCartney, J. S., Zornberg, J. G. \& Swan, R. H. (2005). Effect of geomembrane texturing on GCL-geomembrane interface shear strength. In Waste Containment and Remediation - GeoFrontiers 2005, Alshawabkeh, A., Benson, C. H., Culligan, P. J., Evans, J. C., Gross, B. A., Narejo, D., Reddy, K. R., Shackelford, C. D. \& Zornberg, J. G., Editors, American Society of Civil Engineers, Reston, VA, USA, Geotechncial Special Publication no. 142 (CD-ROM).

McCartney, J. S., Zornberg, J. G. \& Swan, R. H. (2009). Analysis of a large database of GCL-geomembrane interface shear strength results. Journal of Geotechnical and Geoenvironmental Engineering, 135, No. 2, 209-223.

Mitchell, R. A. \& Mitchell, J. K. (1992). Stability evaluation of waste landfills. In Stability of Slopes and Embankments II, Seed, R. B. \& Boulanger, R. W., Editors, American Society of Civil Engineers, New York, NY, USA, Geotechnical Special Publication no. 31, vol. 2, pp. 1152-1187.

Orman, M. E. (1994). Interface shear strength properties of roughened HDPE. Journal of Geotechnical Engineering, 120, No. 4, 758-761.

Palmeira, E. M. (2009). Soil-geosynthetic interaction: Modelling and analysis. Geotextiles and Geomembranes, 27, No. 5, 368-390.

Pitanga, H. N., Gourc, J. P. \& Vilar, O. M. (2009). Interface shear strength of geosynthetics: Evaluation and analysis of inclined plane tests. Geotextiles and Geomembranes, 27, No. 6, 435-446.

Sayeed, M. M. A., Janaki Ramaiah, B. \& Rawal, A. (2014). Interface shear characteristics of jute/polypropylene hybrid nonwoven geotextiles and sand using large size direct shear test. Geotextiles and Geomembranes, 42, No. 1, 63-68.

Seed, R. B. \& Boulanger, R. W. (1991). Smooth HDPE-clay liner interface shear strengths: compaction effects. Journal of Geotechnical Engineering, 117, No. 4, 686-693.

Sharma, J. S., Fleming, I. R. \& Jogi, M. B. (2007). Measurement of unsaturated soil-geomembrane interface shear-strength parameters. Canadian Geotechnical Journal, 44, No. 1, 78-88.

Stark, T. D. \& Poeppel, A. R. (1994). Landfill liner interface strengths from torsional-ring-shear tests. Journal of Geotechnical Engineering, 120, No. 3, 597-615.

Stark, T. D., Williamson, T. A. \& Eid, H. T. (1996). HDPE geomembrane/geotextile interface shear strength. Journal of Geotechnical Engineering, 122, No. 3, 197-203.

Triplett, E. J. \& Fox, P. J. (2001). Shear strength of HDPE geomembrane/ geosynthetic clay liner interfaces. Journal of Geotechnical and Geoenvironmental Engineering, 127, No. 6, 543-552.

Vieira, C. S., Lopes, M. L. \& Caldeira, L. M. (2013). Sand-geotextile interface characterization through monotonic and cyclic direct shear tests. Geosynthetics International, 20, No. 1, 26-38.

Wasti, Y. \& Özdüzgün, Z. B. (2001). Geomembrane-geotextile interface shear properties as determined by inclined board and direct shear box tests. Geotextiles and Geomembranes, 19, No. 1, $45-57$.

Zettler, T. E., Frost, J. D. \& Dejong, J. T. (2000). Shear-induced changes in smooth HDPE geomembrane surface topography. Geosynthetics International, 7, No. 3, 243-267.

Zornberg, J. G., McCartney, J. S. \& Swan, R. H. (2005). Analysis of a large database of GCL internal shear strength results. Journal of Geotechnical and Geoenvironmental Engineering, 131, No. 3, $367-380$. 